\title{
The impact of weight loss related to risk of new-onset atrial fibrillation in patients with type 2 diabetes mellitus treated
} with sodium-glucose cotransporter 2 inhibitor

\author{
Yi-Hsin Chan ${ }^{1,2,3}$, Shao-Wei Chen ${ }^{4,5}$, Tze-Fan Chao ${ }^{6,7}$, Yi-Wei Kao ${ }^{8}$, Chien-Ying Huang ${ }^{1}$ and Pao-Hsien Chu ${ }^{1,2^{*}}$
}

\begin{abstract}
Background: Sodium-glucose cotransporter 2 inhibitor (SGLT2i) use reduces body weight (BW) in patients with type 2 diabetes mellitus (T2DM). Obesity and T2DM are strong risk factors of new-onset atrial fibrillation (AF). However, whether BW loss following SGLT2i treatment reduces AF risk in patients with T2DM remains unclear.

Methods: We used a medical database from a multicenter health care provider in Taiwan, which included 10,237 patients with T2DM, from June 1, 2016 to December 31, 2018, whose BW data at baseline and at 12 weeks of SGLT2i treatment were available. Patients were followed up from the drug index date until the occurrence of new-onset AF, discontinuation of the SGLT2i, or the end of the study period, whichever occurred first.

Results: The patients' baseline body mass index (BMI) was $28.08 \pm 4.88 \mathrm{~kg} / \mathrm{m}^{2}$. SGLT2i treatment was associated with a BW loss of $1.35 \pm 3.28 \mathrm{~kg}(1.78 \% \pm 4.47 \%)$. There were $37.4 \%, 47.0 \%$, and $15.6 \%$ of patients experienced no-BW loss $(n=3832)$, BW loss $0.0-4.9 \%(n=4814)$, and $\geq 5.0 \%(n=1591)$ following SGLT2i treatment, respectively. Compared with patients with baseline $\mathrm{BMl}<23 \mathrm{~kg} / \mathrm{m}^{2}$, AF risk significantly increased in patients with baseline $\mathrm{BMI} \geq 27.5 \mathrm{~kg} / \mathrm{m}^{2}$ ( $P$ for trend $=0.015$ ). Compared with those without BW loss after SGLT2i treatment, AF risk significantly decreased with a BW loss of $\geq 5.0 \%$ (adjusted hazard ratios [95\% confidence intervals]: 0.39[0.22-0.68]). Use of diuretics, old age, highdose SGLT2i, higher estimated glomerular filtration rate, and baseline BMI were independent factors associated with a BW loss of $\geq 5.0 \%$ following SGLT2i initiation. By contrast, neither baseline BMI nor BW loss after SGLT2i treatment predicted major cardiovascular adverse events or heart failure hospitalization risk ( $P$ for trend $>0.05$ ).
\end{abstract}

Conclusion: BW loss of $\geq 5.0 \%$ following SGLT2i treatment was associated with a lower risk of new-onset AF in patients with T2DM in real-world practice.

Keywords: Atrial fibrillation, Type 2 diabetes mellitus, Sodium-glucose cotransporter-2 inhibitor, Heart failure, Obesity

*Correspondence: taipei.chu@gmail.com

${ }^{1}$ The Cardiovascular Department, Chang Gung Memorial Hospital, Linkou, Taoyuan 33305, Taiwan

Full list of author information is available at the end of the article

\section{Background}

Atrial fibrillation (AF), the most common sustained cardiac arrhythmia worldwide, is associated with a fivefold increased ischemic stroke risk and twofold increased mortality risk [1]. Diabetes mellitus (DM) is an independent risk factor for new-onset AF in the general population $[2,3]$. Pathophysiological mechanisms, including atrial

c) The Author(s) 2021. This article is licensed under a Creative Commons Attribution 4.0 International License, which permits use, sharing, adaptation, distribution and reproduction in any medium or format, as long as you give appropriate credit to the original author(s) and the source, provide a link to the Creative Commons licence, and indicate if changes were made. The images or other third party material in this article are included in the article's Creative Commons licence, unless indicated otherwise in a credit line to the material. If material is not included in the article's Creative Commons licence and your intended use is not permitted by statutory regulation or exceeds the permitted use, you will need to obtain permission directly from the copyright holder. To view a copy of this licence, visit http://creativeco mmons.org/licenses/by/4.0/. The Creative Commons Public Domain Dedication waiver (http://creativecommons.org/publicdomain/ zero/1.0/) applies to the data made available in this article, unless otherwise stated in a credit line to the data. 
electrical, structural, neural remodeling, and glycemic fluctuations, may play a crucial role in increased AF risk in patients with DM [4]. Sodium-glucose cotransporter 2 inhibitors (SGLT2is) are a new class of antidiabetic drug that inhibits renal tubular sodium-glucose reabsorption without stimulating insulin release in patients with type 2 DM (T2DM) [5]. Large randomized placebo-controlled trials have concluded that SGLT2is (including canagliflozin, dapagliflozin, and empagliflozin) reduced the risk of major cardiovascular events, heart failure hospitalization, and stabilized renal function consistently in patients with T2DM with or without established cardiovascular diseases [6-8]. Furthermore, post hoc analysis of the DECLARE-TIMI 58 trial and a few real-world data indicated that the use of dapagliflozin and other SGLT2is was associated with a lower new-onset AF/atrial flutter risk than current standard care of antihyperglycemic agents in patients with T2DM $[9,10]$. SGLT2is have multiple pleiotropic effects of glucose-independent and direct cardiac protection, including reduction in inflammation, oxidative stress, endothelial dysfunction, and left ventricular dysfunction, which may improve atrial remodeling and thus reduce AF risk [11, 12]. Long-term sustained weight loss through diet and physical activity modification can significant reduce AF burden and maintain sinus rhythm in obese individuals with AF or those who underwent post-catheter ablation for AF [11, 13]. Furthermore, SGLT2is directly cause body weight (BW) loss through glucose excretion (calorie loss); however, how BW loss affects new-onset AF risk in patients with T2DM remains unclear. Therefore, this study, by using a large real-world database of an Asian population with T2DM, evaluated whether BW loss due to SGLT2i treatment reduces the risk of new-onset AF.

\section{Methods}

\section{Database}

This retrospective observational study was approved by the Institutional Review Board of the Chang Gung Medical Foundation. It was based on data from the Chang Gung Research Database provided by Chang Gung Memorial Hospital (CGMH). The interpretation and conclusions contained herein do not represent the position of CGMH The CGMH Medical System is composed of two medical centers, two regional hospitals, and three district hospitals, with a total of 10,050 beds and approximately 280,000 admissions per year; it is currently the largest health care provider in Taiwan [14]. The advantage of the CGMH medical database detailed data on diagnoses, medications, interventions, laboratory examinations, and imaging are available for each patient [14]. The identification number of each patient is encrypted and de-identified using a consistent encryption procedure; therefore, the need for informed consent was waived for this study.

\section{Study design and outcome}

Figure 1 presents the study design and patient enrollment flowchart. The CGMH Research Database was retrospectively searched for patients aged $\geq 20$ years in whom new-onset T2DM was diagnosed from January 1, 2001, to December 31, $2018(\mathrm{n}=382,839)$. We excluded patients who did not use any antidiabetic drugs $(n=95,622)$ and who had a diagnosis of prevalent AF before T2DM diagnosis $(\mathrm{n}=8,898)$. Among the remaining 258,319 patients, those who had a first prescription for a SGLT2i (approval date: June 1,2016$)$ were enrolled in the present study $(\mathrm{n}=21,480)$. We included only patients with a follow-up period of $>3$ months. We used the BW data nearest to the date of 12 weeks (3 months) after the drug index date as the following-up BW data after SGLT2i treatment, to calculate the change of BW following SGLT2i treatment

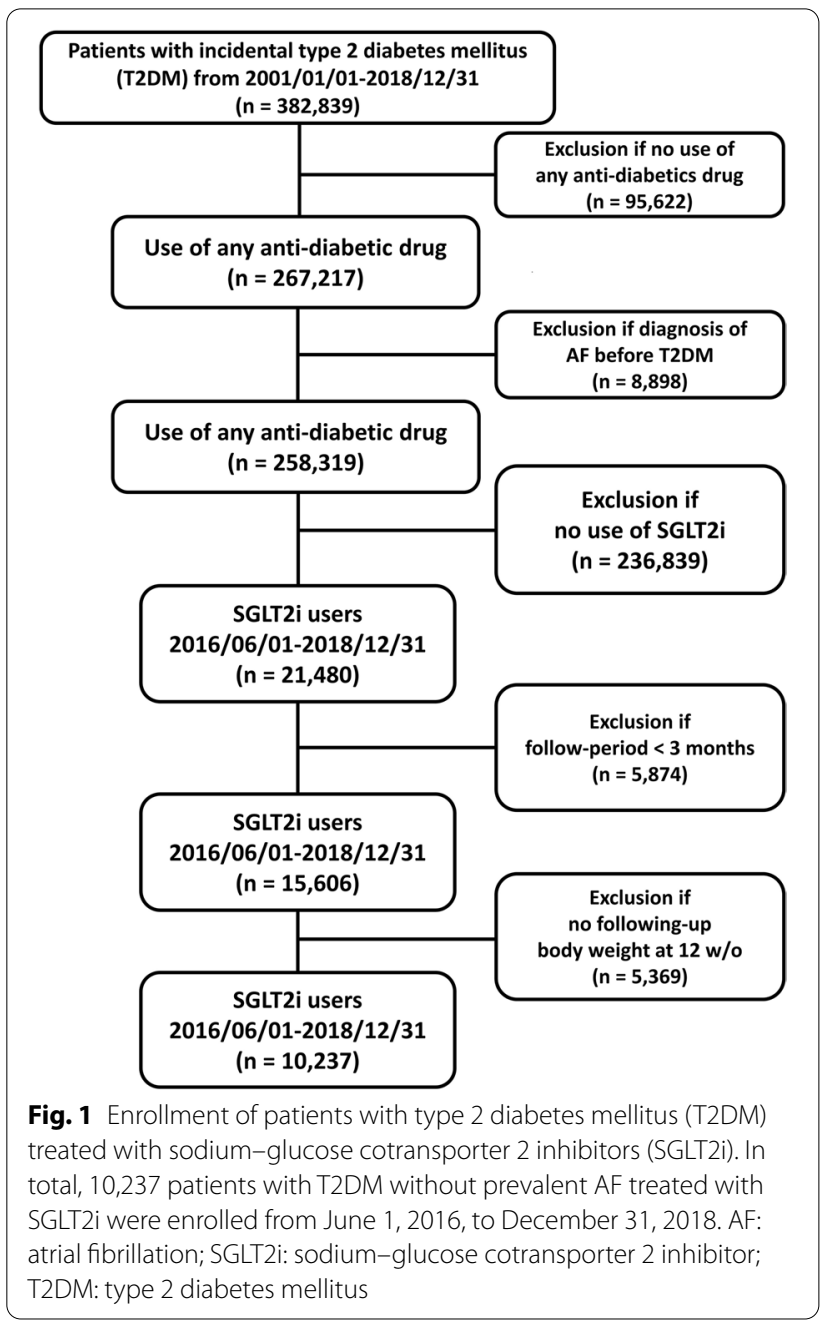


((following-up BW-baseline BW)/baseline BW (\%)). Patients without BW data at baseline and at $\sim 12$ weeks of SGLT2i treatment were excluded. Finally, 10,237 SGLT2i users with paired BW data were considered for analysis. The study outcome was the diagnosis of new-onset AF (International Classification of Diseases, Ninth Revision, Clinical Modification [ICD-9-CM] code 427.31 from January 1, 2010, to December 31, 2015, and ICD-10-CM code I48 from January 1, 2016, to December 31, 2018) in at least one inpatient or outpatient department visit that occurred at least 12 weeks after the drug index date (i.e., the first date of a prescription for a SGLT2i after June 1, 2016). The follow-up period was defined as the period from the index date until the occurrence of new-onset $\mathrm{AF}$, discontinuation of the index drug, mortality, last follow-up date in the CGMH Medical System, or the end of the study period (December 31, 2018), whichever occurred first.

\section{Covariates}

Baseline characteristics referred to any claims record with the aforementioned diagnoses or medication codes prior to the drug index date. A history of any prescription medicine was confined to medications taken at least once within 3 months preceding the index date. Baseline laboratory data listed in Table 1 were based on the measurements performed within 1 year before the drug index date.

\section{Statistical analysis}

Data are presented as mean \pm standard deviation for continuous variables and as proportions for categorical variables. Analysis of variance was used to compare differences in continuous variables, and $\chi^{2}$ test was used to compare the differences in nominal variables. Crude incidence rates were computed as the total number of study outcomes during the follow-up time divided by personyears at risk. Kaplan-Meier method and multivariate Cox proportional hazards regression were used to compare the risk of events in patients with T2DM across different categories based on baseline body mass index (BMI) or BW loss after SGLT2i treatment. Statistical significance was set as $P<0.05$. All analyses were conducted using SAS (version 9.2; SAS Institute, Cary, NC, USA).

\section{Results}

\section{Baseline characteristics of 'baseline BMI' categories}

The mean follow-up period was $1.5 \pm 0.6$ years. Of 10,237 patients, 5492 (54\%), 4739 (46\%), and 6 (0\%) received empagliflozin, dapagliflozin, and canagliflozin, respectively. The mean age and baseline BMI for the study cohort were $58.6 \pm 11.5$ years and $28.1 \pm 4.9 \mathrm{~kg} / \mathrm{m}^{2}$, respectively. We stratified the patients based on their
BMI into the following groups: normal $(\mathrm{BMI}<23.0 \mathrm{~kg} /$ $\mathrm{m}^{2} ; \mathrm{n}=1203$ ), overweight (BMI: 23.0-24.9 $\mathrm{kg} / \mathrm{m}^{2}$; $\mathrm{n}=1518$ ), obese I (BMI: $25.0-27.4 \mathrm{~kg} / \mathrm{m}^{2} ; \mathrm{n}=2465$ ), obese II (BMI: $27.5-29.9 \mathrm{~kg} / \mathrm{m}^{2} ; \mathrm{n}=2026$ ), and obese III (BMI: $\geq 30.0 \mathrm{~kg} / \mathrm{m}^{2} ; \mathrm{n}=3025$ ) subgroups, modified from the WHO Asian BMI classifications [15]. Table 1 summarizes the clinical characteristics of patients with AF stratified by BMI. In general, patients with a higher baseline BMI were younger and predominantly female and had a higher prevalence of hypertension, dyslipidemia, and chronic liver disease. Moreover, a higher percentage of them received antiplatelet agents, beta-blockers, angiotensin-converting-enzyme inhibitors (ACEIs)/angiotensin II receptor antagonists (ARBs), and statins, and a lower percentage of them received insulin or oral hypoglycemic agents $(P<0.0001)$.

\section{Baseline characteristics of 'body weight loss' categories}

Overall, a BW loss of $1.35 \pm 3.28 \mathrm{~kg}(-1.78 \% \pm 4.47 \%)$ was noted in the study patients after 12 weeks of SGLT2i treatment. Patients were divided into three groups according to the amount of BW loss: No BW loss $(\mathrm{n}=3832)$ and BW loss of $0.0-5.0 \%(\mathrm{n}=4814)$, and $\geq$ $5.0 \%(n=1591)$. We used the cutoff value of $5 \%$ loss in BW because clinically significant BW loss was defined as those achieving $\geq 5 \% \mathrm{BW}$ loss from baseline according to previous literatures $[16,17]$ Table 2 summarizes the clinical characteristics of patients with AF stratified by the amount of BW loss. In general, patients with a BW loss $>5 \%$ were older; had a higher prevalence of female in gender, ischemic heart disease, congestive heart failure; and had a higher baseline BMI but a lower HbA1c. Moreover, a higher percentage of them received antiplatelet agent, loop diuretics, and nitrate, but a lower percentage of them received insulin $(P<0.001)$.

\section{Long-term body weight trajectories across study groups}

Among a total of 10,237 patients with a paired BW data at baseline and follow-up period of around 12 weeks, there were 9228 (90.1\%) patients having further followup visits (and BW data) beyond the follow-up date of BW. The median [25\%, 75\%] follow-up period with the last BW data available beyond the follow-up date of BW were 485 [252, 679] days. The log-term BW trajectories for the five study groups of different baseline BMI categories receiving SGLT2 treatment were summarized in Fig. 2a. The respective mean (SE) BW changes from baseline to the 3 months following-up in these 5 groups were -0.67 (0.09), - $1.14(0.07),-1.23$ (0.05), - 1.41 (0.07), and $-1.80(0.07) \mathrm{kg}$. In general, the mean BW remained stable from 3 months onward across all study categories, and there is no difference of the BW slope across 5 study groups $(P=0.712)$ (Fig. 2a). The log-term BW trajectories 
Table 1 Clinical characteristics of patients with type 2 diabetes treated with an SGLT2i stratified by baseline BMI

\begin{tabular}{|c|c|c|c|c|c|c|}
\hline & $\begin{array}{l}\text { Normal } \\
\mathrm{BMI}<23 \\
(\mathrm{n}=1,203)\end{array}$ & $\begin{array}{l}\text { Overweight BMI } \\
23.0-24.9(n=1,518)\end{array}$ & $\begin{array}{l}\text { Obese I BMI 25.0- } \\
27.4(n=2,465)\end{array}$ & $\begin{array}{l}\text { Obese II BMI 27.5- } \\
29.9(n=2,026)\end{array}$ & $\begin{array}{l}\text { Obese III BMI } \geq \\
30.0(n=3,025)\end{array}$ & $P$ value (ANOVA) \\
\hline \multicolumn{7}{|l|}{ Clinical characteristics } \\
\hline Diabetes duration (year) & $8.5 \pm 3.6$ & $8.4 \pm 3.7$ & $8.5 \pm 3.5$ & $8.3 \pm 3.6$ & $7.6 \pm 3.7$ & $<0.001$ \\
\hline Age (year) & $62.0 \pm 10.7$ & $61.1 \pm 10.7$ & $60.0 \pm 10.7$ & $58.9 \pm 10.9$ & $54.6 \pm 12.1$ & $<0.001$ \\
\hline Female & $601(50)$ & $643(42)$ & $1042(42)$ & $768(38)$ & $1290(43)$ & $<0.001$ \\
\hline Ischemic heart etiology & $89(7)$ & $123(8)$ & $215(9)$ & $194(10)$ & $194(6)$ & 0.001 \\
\hline Hypertension & $630(52)$ & $878(58)$ & $1634(66)$ & $1437(71)$ & $2264(75)$ & $<0.001$ \\
\hline Dyslipidemia & $799(66)$ & $1125(74)$ & $1883(76)$ & $1536(77)$ & $2318(77)$ & $<0.001$ \\
\hline Cerebral vascular accidents & $53(4)$ & $75(5)$ & $111(5)$ & $90(4)$ & $110(4)$ & 0.273 \\
\hline Congestive heart failure & $47(4)$ & $42(3)$ & $78(3)$ & $66(3)$ & $98(3)$ & 0.585 \\
\hline Chronic lung disease & $26(2)$ & $29(2)$ & $42(2)$ & $36(2)$ & $89(3)$ & 0.011 \\
\hline Chronic liver disease & $308(26)$ & $353(23)$ & $680(28)$ & $588(29)$ & $912(30)$ & $<0.001$ \\
\hline Chronic kidney disease & $208(17)$ & $248(16)$ & $415(17)$ & $338(17)$ & $543(18)$ & 0.633 \\
\hline Peripheral artery disease & $13(1)$ & $15(1)$ & $22(1)$ & $18(1)$ & $21(1)$ & 0.741 \\
\hline Gout & $70(6)$ & $115(8)$ & $227(9)$ & $241(12)$ & $386(13)$ & $<0.001$ \\
\hline Malignancy & $111(9)$ & $155(10)$ & $203(8)$ & $125(6)$ & $213(7)$ & $<0.001$ \\
\hline \multicolumn{7}{|l|}{ Vital sign } \\
\hline Height (cm) & $160.6 \pm 12.2$ & $161.8 \pm 11.8$ & $161.8 \pm 10.9$ & $162.6 \pm 11.8$ & $162.1 \pm 14.2$ & $<0.001$ \\
\hline Body weight (KG) & $56.6 \pm 7.4$ & $63.8 \pm 6.8$ & $69.2 \pm 7.6$ & $76.5 \pm 8.4$ & $89.3 \pm 14.3$ & $<0.001$ \\
\hline BMI & $21.4 \pm 1.4$ & $24.1 \pm 0.6$ & $26.2 \pm 0.7$ & $28.6 \pm 0.7$ & $33.6 \pm 3.8$ & $<0.001$ \\
\hline $\mathrm{SBP}(\mathrm{mmHg})$ & $133.4 \pm 20.8$ & $136.5 \pm 18.9$ & $138.2 \pm 20.0$ & $140.2 \pm 18.5$ & $142.0 \pm 19.2$ & $<0.001$ \\
\hline $\mathrm{DBP}(\mathrm{mmHg})$ & $73.7 \pm 10.9$ & $76.1 \pm 11.1$ & $77.2 \pm 11.1$ & $78.8 \pm 11.4$ & $80.8 \pm 11.4$ & $<0.001$ \\
\hline $\mathrm{HR}$ (bpm) & $85.0 \pm 13.5$ & $84.0 \pm 13.3$ & $84.0 \pm 13.3$ & $84.4 \pm 13.1$ & $85.8 \pm 13.7$ & $<0.001$ \\
\hline \multicolumn{7}{|l|}{ Baseline laboratory data } \\
\hline HbA1c (\%) & $9.1 \pm 1.8$ & $8.8 \pm 1.6$ & $8.8 \pm 1.6$ & $8.8 \pm 1.6$ & $8.7 \pm 1.6$ & $<0.001$ \\
\hline $\operatorname{eGFR}\left(\mathrm{ml} / \mathrm{min} / \mathrm{m}^{2}\right)$ & $97.1 \pm 33.9$ & $93.6 \pm 29.1$ & $93.0 \pm 30.3$ & $91.7 \pm 28.2$ & $96.1 \pm 29.4$ & $<0.001$ \\
\hline ALT (U/L) & $28.3 \pm 27.3$ & $29.4 \pm 31.3$ & $33.3 \pm 64.0$ & $35.0 \pm 33.6$ & $40.8 \pm 32.3$ & $<0.001$ \\
\hline Triglycerides (mg/dL) & $137.6 \pm 135.0$ & $157.9 \pm 141.0$ & $180.6 \pm 230.6$ & $199.7 \pm 323.8$ & $198.1 \pm 187.9$ & $<0.001$ \\
\hline $\mathrm{LDL}(\mathrm{mg} / \mathrm{dL})$ & $94.9 \pm 30.8$ & $93.3 \pm 29.9$ & $92.2 \pm 30.5$ & $93.7 \pm 31.2$ & $94.4 \pm 29.2$ & 0.050 \\
\hline $\mathrm{HDL}(\mathrm{mg} / \mathrm{d})$ & $48.3 \pm 14.1$ & $45.1 \pm 11.1$ & $43.7 \pm 10.9$ & $42.9 \pm 10.4$ & $42.4 \pm 10.3$ & $<0.001$ \\
\hline \multicolumn{7}{|l|}{ Baseline medications } \\
\hline Anti-platelet agent & $336(28)$ & $494(33)$ & $814(33)$ & $689(34)$ & $958(32)$ & 0.006 \\
\hline Statin & $653(54)$ & $928(61)$ & $1566(64)$ & $1298(64)$ & $1880(62)$ & $<0.001$ \\
\hline Non-dihydropyridine CCB & $52(4)$ & $67(4)$ & $106(4)$ & $131(6)$ & $180(6)$ & 0.001 \\
\hline Dihydropyridine CCB & $135(11)$ & $210(14)$ & $387(16)$ & $330(16)$ & $554(18)$ & $<0.001$ \\
\hline Beta-blocker & $278(23)$ & $421(28)$ & $747(30)$ & $708(35)$ & $1082(36)$ & $<0.001$ \\
\hline ACEl or ARB or ARNI & $527(44)$ & $777(51)$ & $1440(58)$ & $1288(64)$ & $2081(69)$ & $<0.001$ \\
\hline MRA & $30(2)$ & $20(1)$ & $64(3)$ & $57(3)$ & $95(3)$ & 0.008 \\
\hline Loop diuretics & $72(6)$ & $76(5)$ & $156(6)$ & $120(6)$ & $237(8)$ & 0.003 \\
\hline Thiazides & $4(0)$ & $7(0)$ & $13(1)$ & $8(0)$ & $33(1)$ & 0.005 \\
\hline Nitrate & $61(5)$ & $68(4)$ & $150(6)$ & $141(7)$ & $178(6)$ & 0.023 \\
\hline Digoxin & $14(1)$ & $10(1)$ & $21(1)$ & $13(1)$ & $21(1)$ & 0.469 \\
\hline \multicolumn{7}{|l|}{ Anti-diabetic agent } \\
\hline SU & $833(69)$ & $1070(70)$ & $1698(69)$ & $1340(66)$ & $1968(65)$ & 0.001 \\
\hline Metformin & $1061(88)$ & $1357(89)$ & $2253(91)$ & $1850(91)$ & $2762(91)$ & 0.004 \\
\hline Glinide & $61(5)$ & $39(3)$ & $85(3)$ & $61(3)$ & $82(3)$ & 0.001 \\
\hline DPP4i & $655(54)$ & $772(51)$ & $1229(50)$ & $981(48)$ & $1356(45)$ & $<0.001$ \\
\hline Glitazone & $263(22)$ & $351(23)$ & $594(24)$ & $564(28)$ & $803(27)$ & $<0.001$ \\
\hline Acarbose & $297(25)$ & $329(22)$ & $518(21)$ & $406(20)$ & $565(19)$ & $<0.001$ \\
\hline Insulin & $262(22)$ & $258(17)$ & $415(17)$ & $345(17)$ & $478(16)$ & $<0.001$ \\
\hline GLP1 agonist & $3(0)$ & $8(1)$ & $14(1)$ & $10(0)$ & $45(1)$ & $<0.001$ \\
\hline
\end{tabular}


Table 1 (continued)

ACEl: angiotensin-converting enzyme inhibitor; ALT: alanine aminotransferase; ARB: angiotensin receptor blocker; ARNI: angiotensin receptor-neprilysin inhibitor; BMI: body mass index; CCB: calcium channel blocker; DBP: diastolic blood pressure; DPP4i: dipeptidyl peptidase-4 inhibitor; eGFR: estimated glomerular filtration rate; GLP1: glucagon-like peptide 1; HBA1c: hemoglobin A1c; HDL: high-density lipoprotein; HR: heart rate; LDL: low-density lipoprotein; MRA: mineralocorticoid receptor antagonist; SBP: systolic blood pressure; SGLT2i: sodium-glucose co-transporter-2 inhibitor; SU: sulfonylurea

Data are expressed as mean \pm standard deviation or number (\%)

for the three study groups of different BW-loss categories following SGLT2 treatment were summarized in Fig. $2 \mathrm{~b}$. The respective mean (SE) BW changes from baseline to the 3 months following-up in these 3 groups were -1.36 $(0.04),-2.01(0.01)$, and $-5.90(0.08) \mathrm{kg}$. The mean (SE) BW slope from 3 months until the last available measurements among participants receiving SGLT2i was -0.67 $(-0.50),-0.14(-0.13)$, and $0.85(0.23) \mathrm{kg} /$ year in these 3 groups. There is significant difference of the BW slope across 3 study groups $(P=0.046)$ (Fig. $2 b)$.

\section{Predictors of significant body weight loss of $\geq 5 \%$}

Multivariate analysis indicated that the use of diuretics, old age, high-dose SGLT2i, use of empagliflozin rather than dapagliflozin, higher estimated glomerular filtration rate, and higher BMI were independent factors associated with a BW loss of $\geq 5.0 \%$, whereas use of insulin or metformin was independently associated with a lower risk of BW loss of $\geq 5.0 \%$ following SGLT2i initiation (Fig. 3).

\section{Risk for new-onset AF with SGLT2i across study groups}

Compared with those with a baseline BMI of $<23.0 \mathrm{~kg} /$ $\mathrm{m}^{2}$, AF risk significantly increased in patients with baseline BMI of $\geq 27.5 \mathrm{~kg} / \mathrm{m}^{2}$ (adjusted hazard ratios [aHRs; 95\% CIs]: 1.86 [1.03-3.37] for BMI of 27.5-29.9 kg/ $\mathrm{m}^{2}$ and 2.23 [1.24-3.98] for BMI of $\geq 30.0 \mathrm{~kg} / \mathrm{m}^{2}$; $P$ for trend $=0.015$ ) after multivariate adjustment of baseline characteristics. Compared with those without BW loss following SGLT2i treatment, AF risk significantly decreased at a BW loss of $\geq 5.0 \%$ (aHRs [95\% CIs]: 0.39 [0.22-0.68]; $P=0.001$ ) after multivariate adjustment of baseline characteristics (Fig. 4).

Subgroup analysis revealed that $a \geq 5 \%$ decrease in $\mathrm{BW}$ was associated with a lower new-onset AF risk than was a $<5 \%$ reduction in BW across most subgroups ( $P$ for interaction $>0.05$; Fig. 5 ). Furthermore, SGLT2i use was associated with greater reductions in new-onset AF events in patients with normal renal function than in those with impaired renal function ( $P$ for interaction $=0.01$ ).

\section{Risk for major adverse cardiovascular events/heart failure hospitalization with SGLT2i across study groups}

We also assessed the incidence of major adverse cardiovascular events (MACE) or heart failure (HF) hospitalization based on different baseline BMI and posttreatment
BW loss categories. In contrast to the AF outcome, neither baseline BMI nor posttreatment BW loss predicted the risk of MACE or HF hospitalization after multivariate adjustment of baseline characteristics $(P$ for trend $>0.05$; Fig. 6).

\section{Discussion}

This is the first study to investigate the impact of baseline BMI and amount of BW loss after SGLT2i treatment on the risk of new-onset AF in an Asian population with T2DM. The main findings of this study are as follows: (i) Baseline BMI $\geq 27.5 \mathrm{~kg} / \mathrm{m}^{2}$ is independently associated with a significantly increased risk of new-onset AF in patients with T2DM treated with SGLT2i. (ii) A $\geq 5 \%$ reduction in BW after 12-week SGLT2i treatment is independently associated with a significantly lower new-onset AF risk in these patients. (iii) The benefit of $\mathrm{a} \geq 5 \% \mathrm{BW}$ loss associated with SGLT2i treatment in reducing AF risk persisted across all T2DM subgroups, irrespective of underlying comorbidities, baseline BMI, or DM status ( $P$ for interaction $>0.05$ ). (iv) By contrast, neither baseline BMI nor posttreatment $\mathrm{BW}$ loss predicted the risk of MACE/HF in patients with T2DM treated with SGLT2i.

The presence of diabetes is a critical risk factor for cardiovascular events, heart failure hospitalization, and new-onset AF development [2,3]. Overweight and obese patients have an increased new-onset AF risk [18]. Our findings are consistent with the limited studies exploring the relationship between BMI and AF in patients with diabetes. Grundvold et al. reported that baseline overweight $\left(\mathrm{BMI}=25.0-29.9 \mathrm{~kg} / \mathrm{m}^{2}\right)$ and obesity $(\mathrm{BMI} \geq$ $30.0 \mathrm{~kg} / \mathrm{m}^{2}$ ) were associated with a 1.9 -fold and 2.9-fold higher incident AF risk in 7169 patients with T2DM [19]. Kim et al. reported that overweight and obesity were significantly associated with an increased new-onset $\mathrm{AF}$ risk among 842,848 patients with diabetes, and diabetes severity had synergistic effects on new-onset AF risk [20]. Similarly, post hoc analysis of the ACCORD trial also indicated that obesity $\left(\mathrm{BMI}=30.0-39.9 \mathrm{~kg} / \mathrm{m}^{2}\right)$ and severe obesity $\left(B M I \geq 30.0 \mathrm{~kg} / \mathrm{m}^{2}\right)$ are associated with an increased risk of AF in 10,074 patients with T2DM, but the interaction was significant only in men. Taken together, these findings imply that diabetes and obesity may have synergistic effects on incident AF risk, probably because excess adiposity-induced proinflammatory cascade and oxidative stress and diabetes-induced chronic 
Table 2 Clinical characteristics of patients with type 2 diabetes treated with an SGLT2i stratified by changes in body weight (BW)

\begin{tabular}{|c|c|c|c|c|}
\hline & No BW loss $(n=3,832)$ & $\begin{array}{l}\text { BW loss } 0.0-5.0 \% \\
(n=4,814)\end{array}$ & $\begin{array}{l}\text { BW loss } \geq 5.0 \% \\
(n=1,591)\end{array}$ & P value (ANOVA) \\
\hline \multicolumn{5}{|l|}{ Clinical characteristics } \\
\hline Diabetes duration (year) & $8.1 \pm 3.6$ & $8.3 \pm 3.6$ & $8.1 \pm 3.7$ & 0.004 \\
\hline Age (year) & $58.2 \pm 11.6$ & $58.4 \pm 11.3$ & $60.0 \pm 11.8$ & $<0.001$ \\
\hline Female & $1610(42)$ & $2009(42)$ & $725(46)$ & 0.023 \\
\hline Ischemic heart etiology & $313(8)$ & $352(7)$ & $150(9)$ & 0.022 \\
\hline Hypertension & $2564(67)$ & $3231(67)$ & $1048(66)$ & 0.654 \\
\hline Dyslipidemia & $2827(74)$ & $3734(78)$ & $1127(71)$ & $<0.001$ \\
\hline Cerebral vascular accidents & $186(5)$ & $174(4)$ & $79(5)$ & 0.006 \\
\hline Congestive heart failure & $150(4)$ & $108(2)$ & $73(5)$ & $<0.001$ \\
\hline Chronic lung disease & $85(2)$ & $98(2)$ & $39(2)$ & 0.593 \\
\hline Chronic liver disease & $1066(28)$ & $1374(29)$ & $401(25)$ & 0.036 \\
\hline Chronic kidney disease & $711(19)$ & $793(16)$ & $248(16)$ & 0.008 \\
\hline Peripheral artery disease & $32(1)$ & $40(1)$ & $17(1)$ & 0.648 \\
\hline Gout & $409(11)$ & $489(10)$ & $141(9)$ & 0.132 \\
\hline Malignancy & $319(8)$ & $361(7)$ & $127(8)$ & 0.363 \\
\hline \multicolumn{5}{|l|}{ Vital sign } \\
\hline Height (cm) & $162.1 \pm 12.1$ & $162.3 \pm 12.0$ & $160.5 \pm 14.2$ & $<0.001$ \\
\hline Body weight (KG) & $73.3 \pm 15.2$ & $75.3 \pm 15.0$ & $73.5 \pm 15.1$ & $<0.001$ \\
\hline BMI $\left(\mathrm{kg} / \mathrm{m}^{2}\right)$ & $27.6 \pm 4.7$ & $28.3 \pm 4.7$ & $28.1 \pm 4.8$ & $<0.001$ \\
\hline Body weight loss (KG) & $1.4 \pm 2.6$ & $-2.0 \pm 1.0$ & $-5.9 \pm 3.1$ & $<0.001$ \\
\hline $\mathrm{SBP}(\mathrm{mmHg})$ & $138.5 \pm 20.2$ & $139.1 \pm 19.2$ & $139.1 \pm 19.6$ & 0.324 \\
\hline $\mathrm{DBP}(\mathrm{mmHg})$ & $78.0 \pm 12.1$ & $78.1 \pm 11.3$ & $77.7 \pm 11.6$ & 0.403 \\
\hline $\mathrm{HR}(\mathrm{bpm})$ & $84.8 \pm 13.5$ & $84.6 \pm 13.1$ & $84.8 \pm 13.4$ & 0.696 \\
\hline \multicolumn{5}{|l|}{ Baseline laboratory data } \\
\hline $\mathrm{HbA1c}(\%)$ & $9.0 \pm 1.8$ & $8.7 \pm 1.5$ & $8.8 \pm 1.6$ & $<0.001$ \\
\hline $\mathrm{eGFR}\left(\mathrm{ml} / \mathrm{min} / \mathrm{m}^{2}\right)$ & $93.8 \pm 31.7$ & $94.7 \pm 28.3$ & $94.0 \pm 30.3$ & 0.391 \\
\hline $\operatorname{ALT}(\mathrm{U} / \mathrm{L})$ & $34.5 \pm 33.7$ & $34.8 \pm 26.8$ & $34.8 \pm 80.6$ & 0.915 \\
\hline Triglycerides (mg/dL) & $190.6 \pm 247.9$ & $178.5 \pm 222.6$ & $166.2 \pm 142.4$ & 0.001 \\
\hline LDL (mg/dL) & $95.1 \pm 32.2$ & $92.5 \pm 28.8$ & $93.6 \pm 29.3$ & $<0.001$ \\
\hline $\mathrm{HDL}(\mathrm{mg} / \mathrm{d})$ & $43.6 \pm 11.3$ & $44.0 \pm 11.0$ & $44.7 \pm 11.6$ & 0.003 \\
\hline \multicolumn{5}{|l|}{ Baseline medications } \\
\hline Anti-platelet agent & $1192(31)$ & $1541(32)$ & $558(35)$ & 0.017 \\
\hline Statin & $2286(60)$ & $3079(64)$ & $960(60)$ & $<0.001$ \\
\hline Non-dihydropyridine CCB & $210(5)$ & $232(4)$ & $94(6)$ & 0.166 \\
\hline Dihydropyridine CCB & $616(16)$ & $760(16)$ & $230(14)$ & 0.318 \\
\hline Beta-blocker & $1238(32)$ & $1488(32)$ & $510(32)$ & 0.350 \\
\hline ACEl or ARB or ARNI & $203(60)$ & $2896(62)$ & $909(57)$ & 0.074 \\
\hline MRA & $117(3)$ & $99(2)$ & $50(3)$ & 0.005 \\
\hline Loop diuretics & $275(7)$ & $254(5)$ & $132(8)$ & $<0.001$ \\
\hline Thiazides & $22(1)$ & $31(1)$ & $12(1)$ & 0.745 \\
\hline Nitrate & $245(6)$ & $247(5)$ & $106(7)$ & 0.014 \\
\hline Digoxin & $41(1)$ & $30(1)$ & $8(1)$ & 0.025 \\
\hline \multicolumn{5}{|l|}{ Anti-diabetic agent } \\
\hline SU & $2562(67)$ & $3286(68)$ & $1061(67)$ & 0.292 \\
\hline Metformin & 3419 (89) & $4440(92)$ & $1424(90)$ & $<0.001$ \\
\hline Glinide & $123(3)$ & $155(3)$ & $50(3)$ & 0.988 \\
\hline DPP4i & $1826(48)$ & $2409(50)$ & $758(48)$ & 0.054 \\
\hline Glitazone & $941(25)$ & $1235(26)$ & $399(25)$ & 0.504 \\
\hline Acarbose & $802(21)$ & $976(20)$ & $337(21)$ & 0.647 \\
\hline
\end{tabular}


Table 2 (continued)

\begin{tabular}{llllc}
\hline & No BW loss $(\mathbf{n = 3 , 8 3 2 )}$ & $\begin{array}{l}\text { BW loss 0.0-5.0\% } \\
(\mathbf{n = 4 , 8 1 4 )}\end{array}$ & $\begin{array}{l}\text { BW loss } \geq 5 \text {.0\% } \\
(\mathbf{n = 1 , 5 9 1 )}\end{array}$ & $P$ value (ANOVA) \\
\hline Insulin & $798(21)$ & $721(15)$ & $239(15)$ & $<0.001$ \\
GLP1 agonist & $30(1)$ & $36(1)$ & $14(1)$ & 0.874 \\
\hline
\end{tabular}

Data are expressed as mean \pm standard deviation or number (\%)

ACEl: angiotensin-converting enzyme inhibitor; ALT: alanine aminotransferase; ARB: angiotensin receptor blocker; ARNI: angiotensin receptor-neprilysin inhibitor; BMI: body mass index; BWG: body weight gain; BWL: body weight loss; CCB: calcium channel blocker; DBP: diastolic blood pressure; DPP4i: dipeptidyl peptidase-4 inhibitor; eGFR: estimated glomerular filtration rate; GLP1: glucagon-like peptide 1; HBA1c: hemoglobin A1c; HDL: high-density lipoprotein; HR: heart rate; LDL: low-density lipoprotein; MRA: mineralocorticoid receptor antagonist; SBP: systolic blood pressure; SGLT2i: sodium-glucose co-transporter-2 inhibitor; SU: sulfonylurea
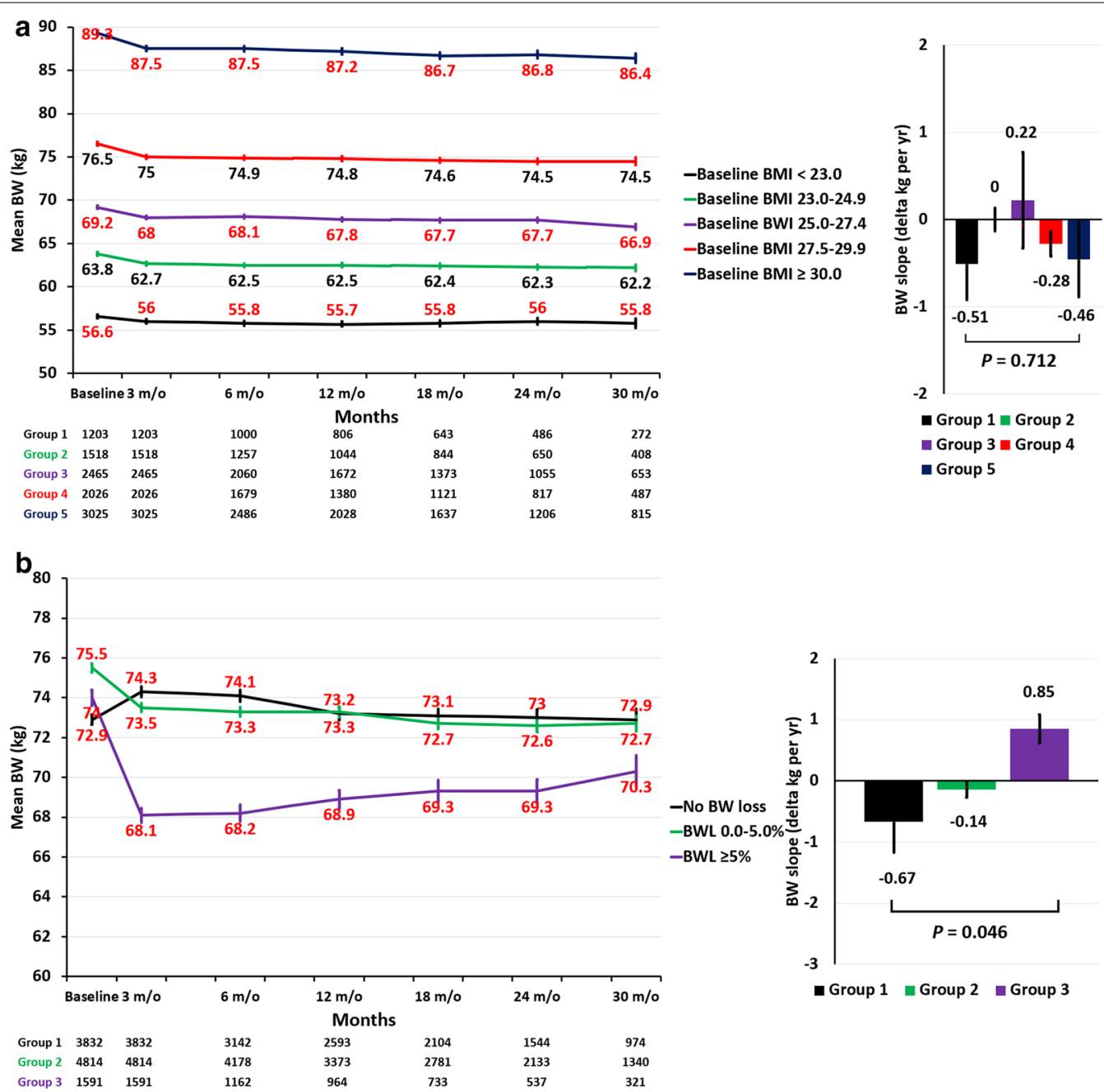

Fig. 2 Long-term body weight (BW) trajectories across study groups. The log-term BW trajectories for the five study groups of different baseline BMI categories receiving SGLT2i treatment remained stable from 3 months onward in all study groups, and there is no difference of the BW slope across 5 study groups ( $P$ : 0.712) (a). The respective mean (SE) BW changes from baseline to the 3 months following-up in these 3 groups of different BW-loss categories following SGLT2i treatment were $1.4(0.04),-2.1(0.14)$, and $-5.9(0.08) \mathrm{kg}$. The mean (SE) BW slope from 3 months until the last available measurements among participants receiving SGLT2i was $-0.67(-0.50),-0.14(-0.13)$, and $0.85(0.23) \mathrm{kg} /$ year in these 3 groups. There is significant difference of the BW slope across 3 study groups $(P=0.046)(\mathbf{b})$. BMI: body mass index; BW: body weight; SE: standard error; SGLT2i: sodium-glucose cotransporter 2 inhibitors 


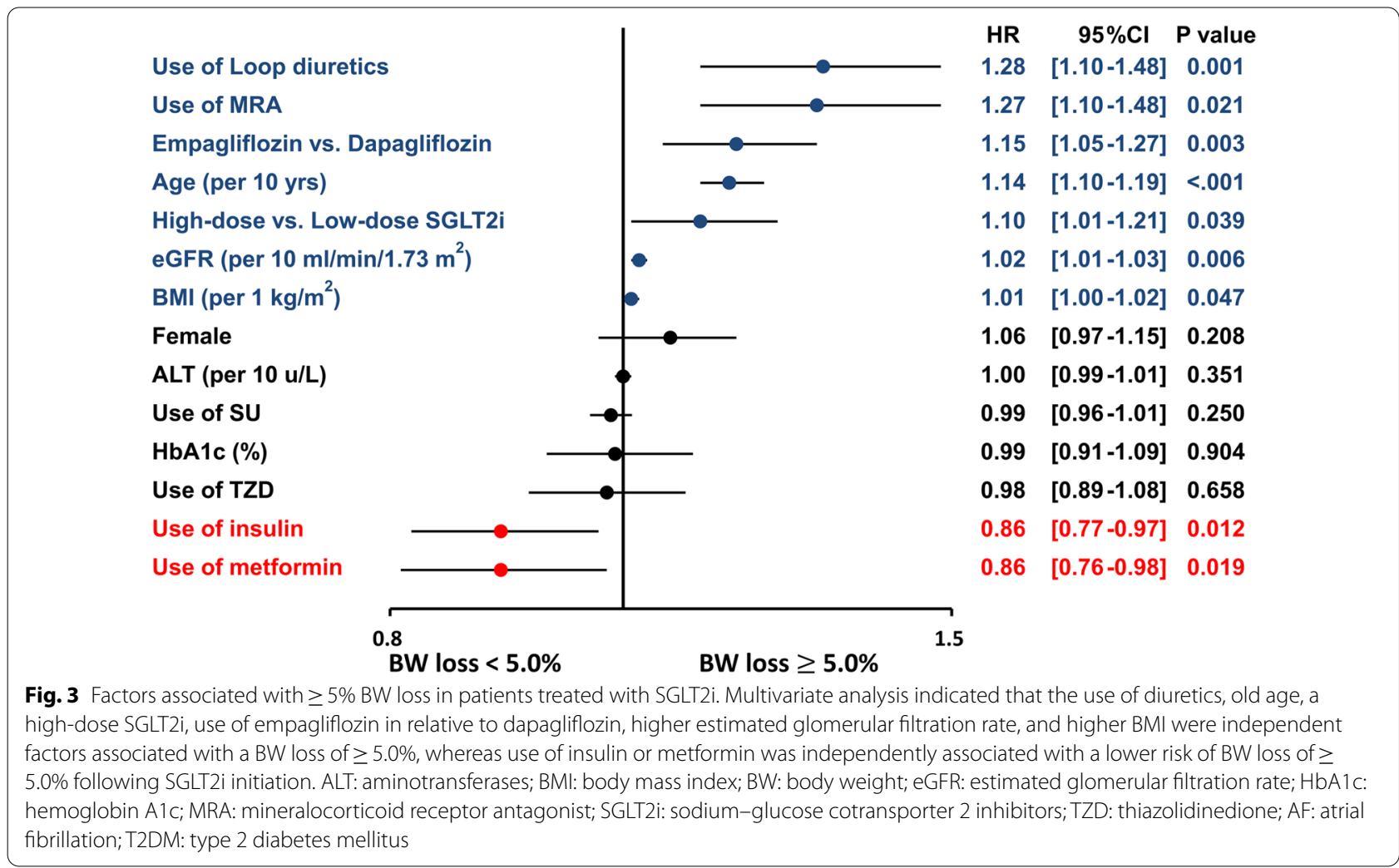

hyperglycemia and glucose fluctuation are both implicated in AF pathogenesis [21-23].

SGLT2is inhibit glucose reabsorption from the proximal renal tubules, resulting in glycosuria [24], the magnitude of which is proportional to the plasma glucose level above the threshold [25]. Moreover, SGLT2is have cardioprotective and renoprotective effects in diabetic or nondiabetic patients through numerous mechanisms of action, independent of their glucose-lowering effect. Notably, post hoc analysis of the DECLARE-TIMI 58 trial and limited observational data reported a reduction in the risk of new-onset AF in patients with T2DM with/without established cardiovascular risk treated with SGLT2i versus those treated with the current standardof-care antihypoglycemic agents $[9,10]$. Although how SGLT2i reduces AF risk remains unclear, limited clinical and experimental studies have proposed a few explanations. At the cellular level, AF upregulates $\mathrm{Na}^{+} / \mathrm{H}^{+}$ exchanger (NHE). Empagliflozin and cariporide, a welldescribed selective NHE inhibitor, both directly inhibit NHE in human atrial cardiomyocytes to a comparable extent [26]. NHE activation resulted in the accumulation of intracellular $\mathrm{Na}^{+}$, which reduces/reverses the driving force of the $\mathrm{Na}^{+} / \mathrm{Ca}^{2+}$ exchanger-mediated $\mathrm{Ca}^{2+}$ efflux, leading to intracellular $\mathrm{Ca}^{2+}$ overload and consequent atrial arrhythmia. Oxidative stress and inflammation were involved in the mechanisms of the promotion of electrical and structural substrates for AF [27]. Yurista et al. [28] demonstrated that SGLT2is can restore mitochondrial function, ameliorate electrical and structural remodeling, and prevent AF in high-fat diet- induced or streptozotocin-induced diabetic rats. Epicardial fat may infiltrate into the atrial myocardium, which could disrupt the depolarization wave front, favoring microre-entry circuits and causing local conduction block; this mechanism is also implicated in AF pathogenesis [29]. Some studies have reported that epicardial adipose tissue volume significantly decreased after 6 -month SGLT2i treatment compared with the conventional treatment in patients with T2DM with coronary artery disease [30]. SGLT2is also reduced sympathetic overdrive, which plays a vital role in the development and maintenance of AF [31]. SGLT2is also exhibit some blood pressurelowering effect and promote diuresis and natriuresis and hence could reduce atrial dilation and consequent atrial arrhythmia [32]. Obesity is an independent risk factor of incident AF, and BW loss following SGLT2i is thus proposed to be one of the important factors directly associated with the reduction of AF incidence. BW loss (either fat mass or free water loss) following SGLT2i treatment may be also associated with a reduction of blood pressure, reduced atrial dilation due to natriuresis 

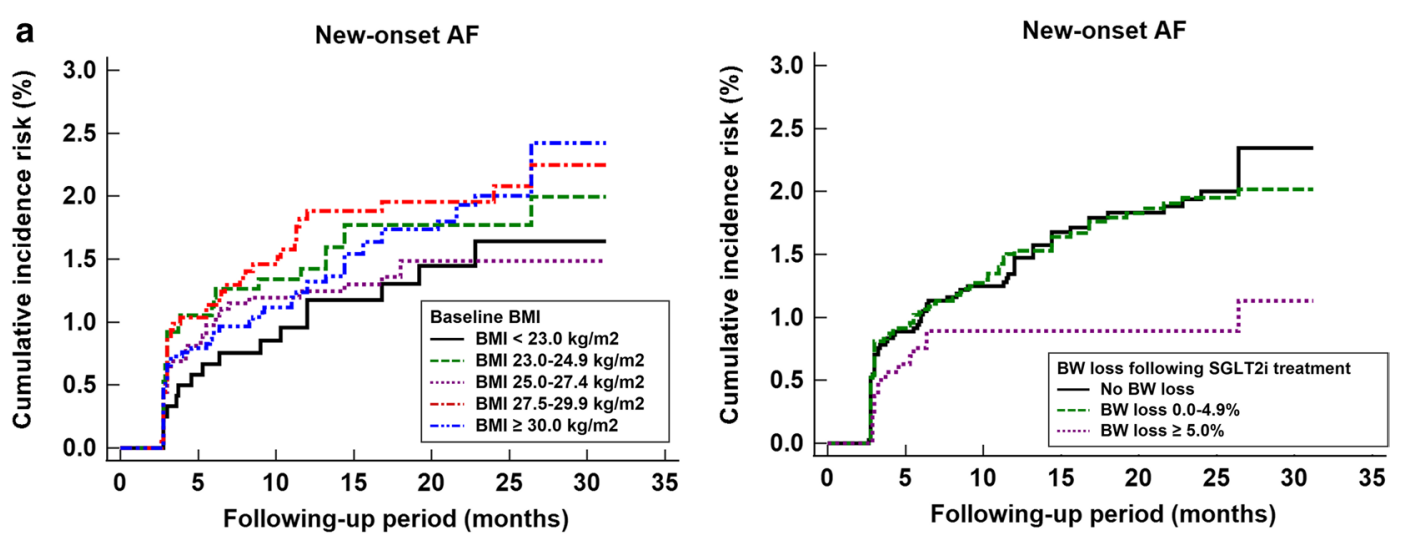

b

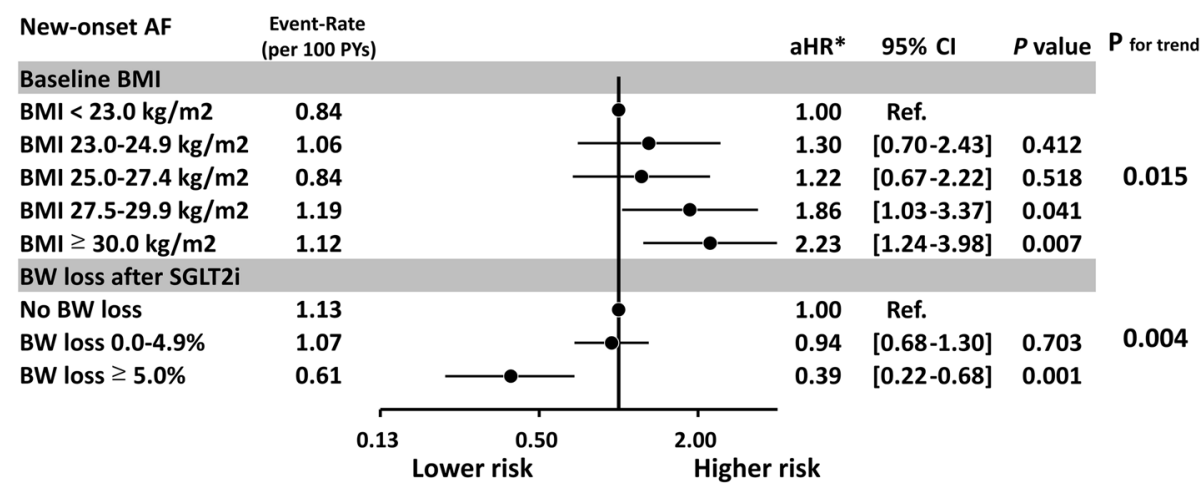

Fig. 4 New-onset AF risk in patients with T2DM in different categories of baseline BMI and BW loss after SGLT2i treatment. Cumulative incidence risk of new-onset AF for T2DM patients in different categories of baseline BMI and BW loss following SGLT2i treatment. a Compared with those with a baseline $B M I$ of $<23 \mathrm{~kg} / \mathrm{m}^{2}$, AF risk significantly increased at baseline $\mathrm{BMI} \geq 27.5 \mathrm{~kg} / \mathrm{m}^{2}$ after multivariate adjustment $(P$ for trend $=0.015)$. Compared with those without BW loss after 12 weeks of SGLT2i treatment, AF risk significantly decreased at a BW loss of $\geq 5.0 \%$ after multivariate adjustment ( $P$ for trend $=0.004$ ). $\mathbf{b}$ *Risk of outcome was adjusted for age, sex, different SGLT2i drugs and dosage, baseline comorbidities as shown in Tables 1, 2, HbA1c, eGFR, and use of antiplatelet therapy, statin, angiotensin system inhibitor, and all anti-hypoglycemic agents. AF: atrial fibrillation; Cl: confidence interval; eGFR: estimated glomerular filtration rate; HbA1c: glycated hemoglobin A1 c; aHR: adjusted hazard ratio; SGLT2i: sodium-glucose cotransporter 2 inhibitor; T2DM: type 2 diabetes mellitus; BMI: body mass index; BW: body weight; SE: standard error; MRA: mineralocorticoid receptor antagonist; TZD: thiazolidinedione

and diuresis, and a reduction of sympathetic overactivity, which can partially explain how SGLT2i reduce the risk of AF. There were several protection mechanisms which may not be directly related to the effect of BW loss following SGLT2i treatment, including the reduction of epicardial fat, promotion of mitochondrial biogenesis, reduction of reactive oxygen species, inhibition of sodium-proton exchanger, improvement of hyperuricemia and hypomagnesemia, and improvement of insulin resistance, also suggested a few possible explanations for the anti-arrhythmic effect noted with SGLT2i [32].

Although obesity is known to be associated with the risk of new-onset incident $\mathrm{AF}$, whether intentional $\mathrm{BW}$ loss can reduce AF risk remained uncertain. Studies have indicated that sustained BW loss dose-dependently reduced the burden of $\mathrm{AF}$ and symptom severity in patients with established AF [11, 13]. However, these studies might have been limited by overweight individuals with established AF. Moreover, whether BW loss can reduce new-onset AF risk in the general population without AF remains unclear. The Look AHEAD randomized controlled trial studied 5067 overweight or obese individuals with T2DM without prevalent AF. Although the intensive lifestyle intervention group achieved a mean percentage BW loss of $6.0 \%$ compared with $3.5 \%$ in the control group, no difference was noted in the risk for the risk of new-onset AF (hazard ratio [HR]: 0.99) [33]. Ball et al. reported that a decrease in $\mathrm{BMI}$ over time was associated with decreased AF risk and vice versa in 14,652 individuals over 10 years follow-up [34]. Berkovitch et al. reported that each $1 \mathrm{~kg} /$ $\mathrm{m}^{2}$ reduction in BMI during follow-up was associated with a significant $7 \%$ reduction in the risk for the first attack of AF among 18,290 middle-aged adults [35]. Jamaly et al. reported that large amounts of BW loss through bariatric surgery reduced AF risk by $29 \%$ 


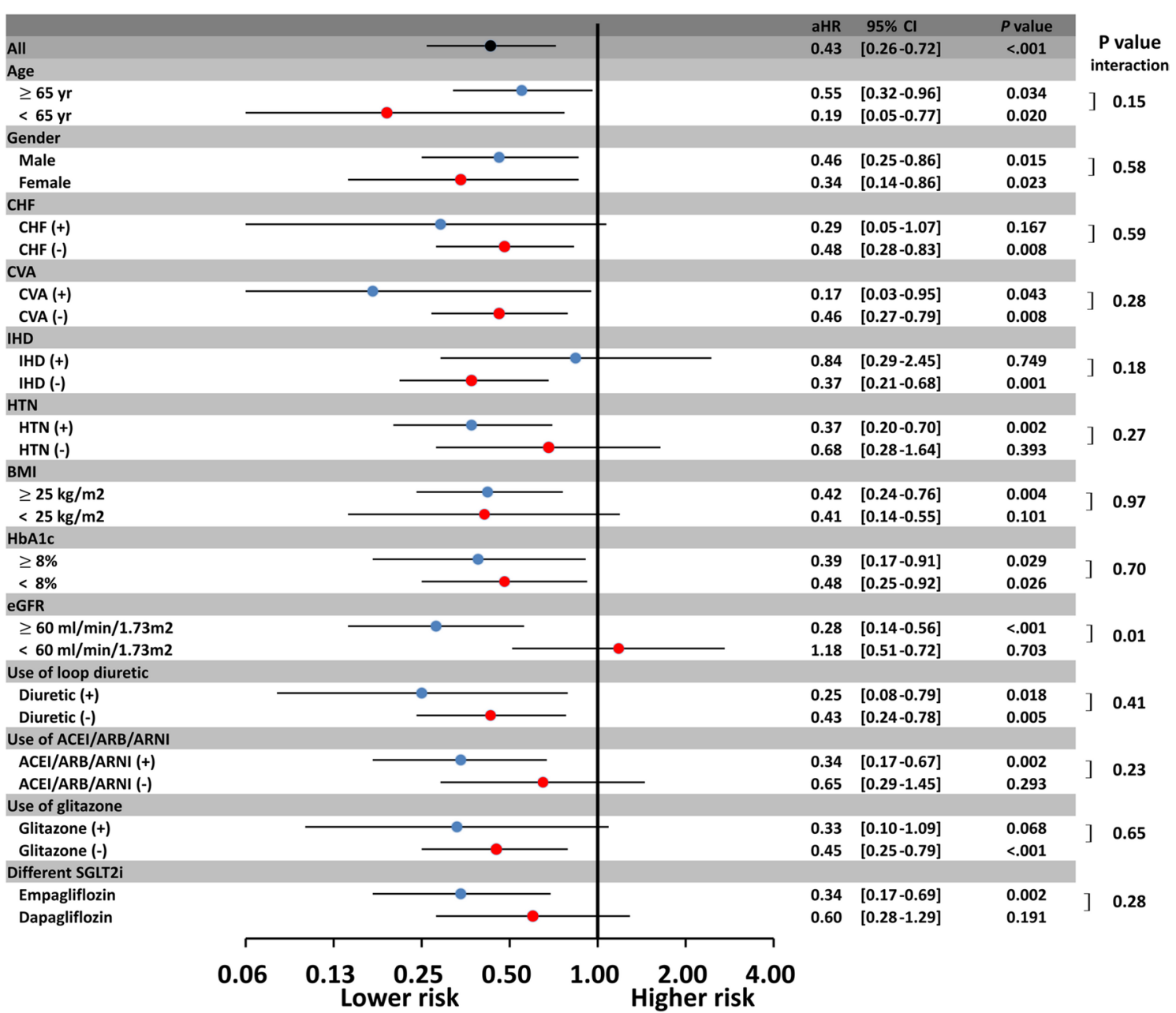

Fig. 5 Subgroup analysis of risk of $\geq 5 \%$ BW loss on AF incidence in patients with T2DM treated with SGLT2i. The benefit of BW loss associated with SGLT2i treatment in the reduction of AF risk persisted across most T2DM subgroups, regardless of underlying comorbidities, baseline BMI, or different HbA1c. Notably, SGLT2i use was associated with greater reductions in new-onset AF events in patients with normal renal function than in those with impaired renal function ( $P$ for interaction $=0.01$ ). ACEl: angiotensin-converting enzyme inhibitor; ARB: angiotensin receptor blocker; ARNI: angiotensin receptor-neprilysin inhibitor; BMI: body mass index; CHF: congestive heart failure; CVA: cerebral vascular disease; eGFR: estimated glomerular filtration rate; $\mathrm{HbA1c}$ : hemoglobin A1c; $\mathrm{HTN}$ : hypertension; IHD: ischemic heart disease AF: atrial fibrillation; Cl: confidence interval; eGFR: estimated glomerular filtration rate; HbA1c: glycated hemoglobin A1c; aHR: adjusted hazard ratio; SGLT2i: sodium-glucose cotransporter 2 inhibitor; T2DM: type 2 diabetes mellitus; BMI: body mass index; BW: body weight; SE: standard error; MRA: mineralocorticoid receptor antagonist; TZD: thiazolidinedione

compared with usual care over long-term follow-up [36]. By contrast, Huxley et al. concluded that BW loss $>5 \%$ was associated with an increased AF risk in 14,219 participants from the ARIC study [37]. A recent meta-analysis of five pooled studies revealed that a $5 \%$ BW loss using a nonsurgical approach was not associated with a significant reduction in AF incidence (HR: 1.04) [38]. Whether intentional BW loss can diminish the risk of new-onset AF remains uncertain and may be related to the amount of BW loss, amount of overweight/obese population, and type of interventional approach $[11,38]$.
Thus far, only SGLT2is, glucagon-like peptide-1 (GLP1) receptor agonists, and metformin lead to BW loss, largely accounted for by body fat reduction [39], whereas other oral hypoglycemic agents and insulin have long been associated with BW gain in patients with T2DM [40, 41]. Most GLP1 agonists demonstrated cardiovascular benefit in the cardiovascular outcome trials [42-44]. GLP1 agonists also demonstrated multiple cardiovascular benefits, including an improvement of blood pressure and lipid profile; however, their use was associated with an increase of resting heart rate [45], possibly due to the augmented sympathetic nervous system activation directly mediated 

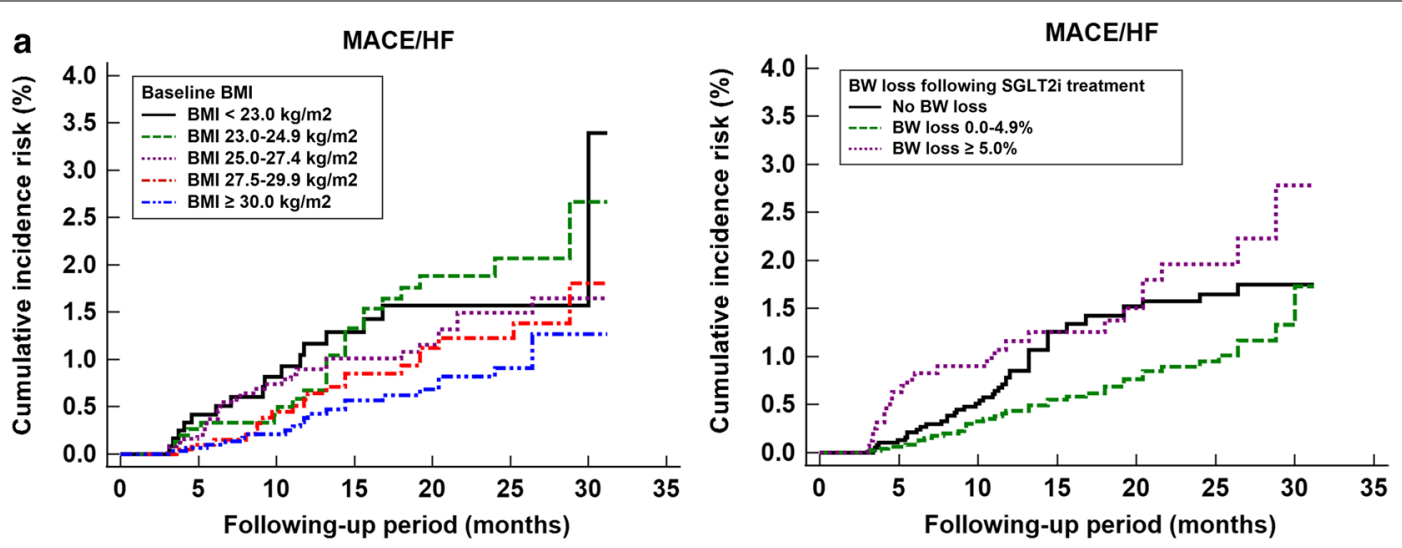

b

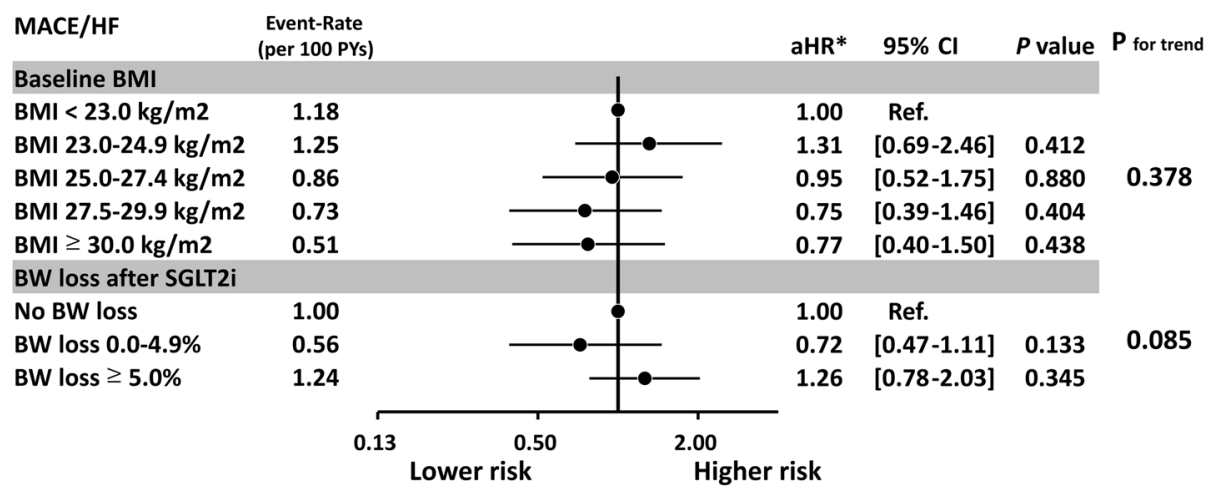

Fig. 6 Major adverse cardiovascular event (MACE) or heart failure (HF) hospitalization risk in patients with T2DM in different categories of baseline BMI and BW loss following SGLT2i treatment. Cumulative incidence risk of MACE/HF for T2DM patients in different categories of baseline BMI and BW loss following SGLT2i treatment. a Neither baseline BMI nor posttreatment BW loss predicted the risk of MACE/HF hospitalization after multivariate adjustment ( $P$ for trend $>0.05$ ). $\mathbf{b}$ *Risk of outcome was adjusted for age, sex, different SGLT2i drugs and dosage, baseline comorbidities as shown in Tables 1, 2, HbA1c, eGFR, and use of antiplatelet therapy, statin, angiotensin system inhibitor, and all anti-hypoglycemic agents. HF: heart failure; MACE: major adverse cardiovascular event AF: atrial fibrillation; Cl: confidence interval; eGFR: estimated glomerular filtration rate; HbA1c: glycated hemoglobin A1 c; aHR: adjusted hazard ratio; SGLT2i: sodium-glucose cotransporter 2 inhibitor; T2DM: type 2 diabetes mellitus; BMI: body mass index; BW: body weight; SE: standard error; MRA: mineralocorticoid receptor antagonist; TZD: thiazolidinedione

by GLP1 agonist [46]. Of note, previous meta-analysis indicated that patients treated with albiglutide was associated with a higher risk of AF or atrial flutter than all-comparators group [47], while other meta-analyses suggested that other GLP1 agonists were not associated with AF, with the only possible exception of albiglutide [48]. Therefore, whether GLP1 agonist could lead to a reduced risk of new-onset AF among patients with T2DM treated with/without SGLT2i remains unclear and requires further elucidation in the future. Our study is the first to report that BW loss associated with SGLT2i treatment was associated with a lower incident AF risk in patients with T2DM without AF. Notably, the benefit of significant BW loss associated with SGLT2i treatment in AF risk reduction persisted across most T2DM subgroups irrespective of baseline BMI, DM severity, and comorbidities. Further prospective and randomized research clarifying our results is warranted.
The multivariate analysis indicated that old age and a higher BMI at baseline were independent factors associated with a BW loss of $\geq 5.0 \%$ (Fig. 3). It is speculated that compensatory hyperphagia probably accounts for the partial off-set of BW loss mediated by SGLT2i [49]. Previous studies showed that younger diabetic patients complied worse with recommended diet and medication regimen for T2DM [50], which may partially explain why the cohort without BW reduction following SGLT2i treatment was significantly younger at baseline. It is also speculated that patients with a lower $\mathrm{BMI}$ at baseline tend to eat more to prevent further $\mathrm{BW}$ loss, in response to the urinary glucose excretion and associated caloric loss mediated by SGLT2i treatment. However, the causality between age or BMI and the diversity of BW loss following SGLT 2i treatment is unclear due to the retrospective and observational nature of the present study. 
In contrast to the impact of new-onset $\mathrm{AF}$, our study demonstrated that neither baseline BMI nor BW loss after SGLT2i treatment affected the risk of MACE/ HF hospitalization in patients with T2DM treated with SGLT2i. This finding agreed with a recent analysis reporting that sustained BW loss was not associated with a lower risk of MACE/HF hospitalization among 12,521 prediabetes or T2DM participants from the ORIGIN trial [51]. The Look AHEAD trial applied a comprehensive lifestyle intervention program to overweight patients with type 2DM. Although an intensive lifestyle intervention focusing on $\mathrm{BW}$ loss resulted in greater reductions in glycated hemoglobin and greater initial improvements in all cardiovascular risk factors (except for low-densitylipoprotein cholesterol levels), it did not reduce the risk of cardiovascular events in the 5145 overweight or obese patients with T2DM [52]. Although the SGLT2i-meditated reduction in cardiovascular risk in patients with T2DM is often partially attributed to BW loss, our analysis indicated other mechanisms, including reductions in hyperglycemia, osmotic diuresis, reduced blood pressure, and renal protection, may play more crucial roles in the reduction of cardiovascular events in these patients [53].

\section{Study limitations}

This study has several limitations. First, this was a retrospective and observational study. Several important parameters related to BW change [54], including physical activity or sedentary behavior, dietary behavior or component, use of alcohol or tobacco, and family history, were lacking in the present study. In addition, the BW check-up for each patient was not mandatory for each clinical visit time, which may cause a lack of BW data for some patients at specific time during their whole follow-up period. Furthermore, the clinical characteristics of the study patients were different across different categories of baseline BMI or posttreatment BW loss. Although we adjusted for several critical parameters relevant to clinical outcomes in the multivariate Cox regression models, some confounders were still probably present. Future prospective randomized studies are necessary to verify our findings. Second, the CGMH datasets is a closed medical system without external link to protect each patient's privacy in CGMH database, which make us difficult to obtain the medical activity of each patient outside the CGMH database in Taiwan. The aforementioned limitation may have resulted in loss to follow-up or underestimation of medical activity of patients outside the CGMH system [55]. Third, the present study did not consider changes in the patients' medical status or activity (e.g., new diagnosis of comorbidities, eGFR decline, and discontinuation or add-on of co-medication) during the follow-up period, which may affect the outcome. Finally, the database comprised an Asian population. In Asia, some obesity related comorbidities are similar or more prevalent in Asians than in Caucasians, even though Asians have lower prevalence of overweight and obesity than their Western counterparts [56]. In addition, the body composition and body fat distribution are different between Asian and Western populations [57]. Therefore, whether our results can be extrapolated to non-Asian population remains unclear.

\section{Conclusions}

A baseline BMI of $\geq 27.5 \mathrm{~kg} / \mathrm{m}^{2}$ and $\mathrm{a} \geq 5 \%$ BW loss following SGLT2i treatment are independently associated with a significantly lower risk of new-onset AF in patients with T2DM treated with SGLT2i. The benefit of $\geq 5 \%$ BW loss following SGLT2i treatment in reduction of AF risk persisted across most T2DM subgroups, irrespective of underlying comorbidities, baseline BMI, or DM status. By contrast, neither baseline BMI nor BW loss after SGLT2i treatment were associated with major cardiovascular event or heart failure hospitalization risk in patients with T2DM treated with SGLT2i.

\section{Abbreviations}

ACEl: Angiotensin-converting enzyme inhibitor; AF: Atrial fibrillation; ACEl: Angiotensin-converting enzyme inhibitor; ALT: Alanine aminotransferase; $A$ ARB Angiotensin receptor blocker; ARNI: Angiotensin receptor-neprilysin inhibitor; AMI: Acute myocardial infarction; APT: Antiplatelet agent; BMI: Body mass index; BW: Body weight; CKD: Chronic kidney disease; DBP: Diastolic blood pressure; DM: Diabetes mellitus; DPP4i: Dipeptidyl peptidase-4 inhibitor; eGFR: Estimated glomerular filtration rate; GLP1: Glucagon-like peptide-1; HbA1c: Hemoglobin A1c; HDL: High-density lipoprotein; IHD: Ischemic heart disease; LDL: Low-density lipoprotein; MRA: Mineralocorticoid Receptor Antagonist; PAD: Peripheral artery disease; SBP: Systolic blood pressure; SGLT2i: Sodiumglucose cotransporter-2 inhibitor; SU: Sulfonylurea; T2DM: Type 2 diabetes mellitus.

\section{Acknowledgements}

The authors are grateful for the statistical assistance and support from the Maintenance Project of the Center for Big Data Analytics and Statistics (Grant CLRPG3D0046) at Chang Gung Memorial Hospital, regarding help with the study design and monitoring, data analysis, and interpretation.

\section{Disclosures}

The authors have nothing to disclose.

\section{Authors' contributions}

YHC, SWC, and TFC contributed to the conception and design of the study, analysis and interpretation of the data, wrote the manuscript, and approved submission. YWK contributed to the data acquisition and analysis. YWK and $\mathrm{CYH}$ collected the data and contributed to analysis of data. YHC and PHC provided critical revision of the paper for important intellectual content. All authors read and approved the final manuscript.

\section{Funding}

This study was supported by grants 108-2314-B-182-053-MY2 from the Ministry of Science and Technology and grants CMRPG3J1371, CMRPG3J1372, CMRPG3E1681, CMRPG3E1682, CMRPG3E1683, and CORPG3G0351 from Chang Gung Memorial Hospital, Linkou, Taiwan. 


\section{Availability of data and materials}

The datasets used in this study were only available in the Chang Gung Medical Data Center, Taiwan. The SAS programs (codes) involved for this study are available from the corresponding author on reasonable request.

\section{Declarations}

\section{Ethics approval and consent to participate}

The study protocol complies with the Declaration of Helsinki and was approved by the Institutional Review Board of the Chang Gung Medical Foundation.

\section{Consent for publication}

Not applicable.

\section{Competing interests}

The authors declare that they have no competing interests.

\section{Author details}

${ }^{1}$ The Cardiovascular Department, Chang Gung Memorial Hospital, Linkou, Taoyuan 33305, Taiwan. ${ }^{2}$ College of Medicine, Chang Gung University, Taoyuan 33302, Taiwan. ${ }^{3}$ Microscopy Core Laboratory, Chang Gung Memorial Hospital, Linkou, Taoyuan, Taiwan. ${ }^{4}$ Division of Thoracic and Cardiovascular Surgery, Department of Surgery, Linkou Medical Center, Chang Gung Memorial Hospital, Chang Gung University, Taoyuan City, Taiwan. ${ }^{5}$ Center for Big Data Analytics and Statistics, Linkou Medical Center, Chang Gung Memorial Hospital, Taoyuan City, Taiwan. 'Division of Cardiology, Department of Medicine, Taipei Veterans General Hospital, Taipei, Taiwan. ${ }^{7}$ Institute of Clinical Medicine, Cardiovascular Research Center, National Yang Ming Chiao Tung University, Taipei, Taiwan. ${ }^{8} \mathrm{Graduate}$ Institute of Business Administration, College of Management, Fu Jen Catholic University, Taipei, Taiwan.

Received: 10 March 2021 Accepted: 20 April 2021

Published online: 30 April 2021

\section{References}

1. January CT, Wann LS, Calkins H, Chen LY, Cigarroa JE, Cleveland JC Jr, Ellinor PT, Ezekowitz MD, Field ME, Furie KL, et al. 2019 AHA/ACC/HRS focused update of the 2014 AHA/ACC/HRS guideline for the management of patients with atrial fibrillation: a report of the American College of Cardiology/American heart association task force on clinical practice guidelines and the heart rhythm society in collaboration with the society of thoracic surgeons. Circulation. 2019;140(2):e125-51.

2. Bell DSH, Goncalves E. Atrial fibrillation and type 2 diabetes: Prevalence, etiology, pathophysiology and effect of anti-diabetic therapies. Diabetes Obes Metab. 2019;21(2):210-7.

3. Huxley RR, Filion KB, Konety S, Alonso A. Meta-analysis of cohort and case-control studies of type 2 diabetes mellitus and risk of atrial fibrillation. Am J Cardiol. 2011;108(1):56-62.

4. Wang A, Green JB, Halperin JL, Piccini JP Sr. Atrial fibrillation and diabetes mellitus: JACC review topic of the week. J Am Coll Cardiol. 2019;74(8):1107-15.

5. Zelniker TA, Braunwald E. Cardiac and renal effects of sodium-glucose co-transporter 2 inhibitors in diabetes: JACC State-of-the-Art review. J Am Coll Cardiol. 2018:72(15):1845-55.

6. Zinman B, Wanner C, Lachin JM, Fitchett D, Bluhmki E, Hantel S, Mattheus M, Devins T, Johansen OE, Woerle HJ, et al. Empagliflozin, cardiovascular outcomes, and mortality in type 2 diabetes. N Engl J Med. 2015:373(22):2117-28.

7. Neal B, Perkovic V, Mahaffey KW, de Zeeuw D, Fulcher G, Erondu N, Shaw W, Law G, Desai M, Matthews DR, et al. Canagliflozin and cardiovascular and renal events in type 2 diabetes. N Engl J Med. 2017;377(7):644-57.

8. Wiviott SD, Raz I, Bonaca MP, Mosenzon O, Kato ET, Cahn A, Silverman MG, Zelniker TA, Kuder JF, Murphy SA, et al. Dapagliflozin and cardiovascular outcomes in Type 2 diabetes. N Engl J Med. 2019;380(4):347-57.

9. Zelniker TA, Bonaca MP, Furtado RHM, Mosenzon O, Kuder JF, Murphy SA, Bhatt DL, Leiter LA, McGuire DK, Wilding JPH, et al. Effect of dapagliflozin on atrial fibrillation in patients with type 2 diabetes mellitus: insights from the DECLARE-TIMI 58 trial. Circulation. 2020;141(15):1227-34.

10. Ling AW, Chan CC, Chen SW, Kao YW, Huang CY, Chan YH, Chu PH. The risk of new-onset atrial fibrillation in patients with type 2 diabetes mellitus treated with sodium glucose cotransporter 2 inhibitors versus dipeptidyl peptidase-4 inhibitors. Cardiovasc Diabetol. 2020;19(1):188.

11. Lavie CJ, Pandey A, Lau DH, Alpert MA, Sanders P. Obesity and atrial fibrillation prevalence, pathogenesis, and prognosis: effects of weight loss and exercise. J Am Coll Cardiol. 2017;70(16):2022-35.

12. Shao Q, Meng L, Lee S, Tse G, Gong M, Zhang Z, Zhao J, Zhao Y, Li G, Liu T. Empagliflozin, a sodium glucose co-transporter-2 inhibitor, alleviates atrial remodeling and improves mitochondrial function in high-fat diet/ streptozotocin-induced diabetic rats. Cardiovasc Diabetol. 2019;18(1):165.

13. Pathak RK, Middeldorp ME, Meredith M, Mehta AB, Mahajan R, Wong CX, Twomey D, Elliott AD, Kalman JM, Abhayaratna WP, et al. Longterm effect of goal-directed weight management in an atrial fibrillation cohort: a long-term follow-up study (LEGACY). J Am Coll Cardiol. 2015;65(20):2159-69.

14. Shao SC, Chan YY, Kao Yang YH, Lin SJ, Hung MJ, Chien RN, Lai CC, Lai EC. The chang gung research database-a multi-institutional electronic medical records database for real-world epidemiological studies in Taiwan. Pharmacoepidemiol Drug Saf. 2019;28(5):593-600.

15. Girdhar S, Sharma S, Chaudhary A, Bansal P, Satija M. An epidemiological study of overweight and obesity among women in an urban area of North India. Indian J Community Med. 2016:41(2):154-7.

16. Donnelly JE, Blair SN, Jakicic JM, Manore MM, Rankin JW, Smith BK. American College of Sports M: American College of Sports Medicine Position Stand. Appropriate physical activity intervention strategies for weight loss and prevention of weight regain for adults. Med Sci Sports Exerc. 2009;41(2):459-71.

17. Swift DL, Johannsen NM, Lavie CJ, Earnest CP, Blair SN, Church TS. Effects of clinically significant weight loss with exercise training on insulin resistance and cardiometabolic adaptations. Obesity. 2016;24(4):812-9.

18. Goudis CA, Korantzopoulos P, Ntalas IV, Kallergis EM, Ketikoglou DG. Obesity and atrial fibrillation: a comprehensive review of the pathophysiological mechanisms and links. J Cardiol. 2015;66(5):361-9.

19. Grundvold I, Bodegard J, Nilsson PM, Svennblad B, Johansson G, Ostgren CJ, Sundstrom J. Body weight and risk of atrial fibrillation in 7,169 patients with newly diagnosed type 2 diabetes; an observational study. Cardiovasc Diabetol. 2015;14:5.

20. Kim YG, Han KD, Choi J, Boo KY, Kim DY, Oh SK, Lee KN, Shim J, Kim JS, Kim YH. The impact of body weight and diabetes on new-onset atrial fibrillation: a nationwide population based study. Cardiovasc Diabetol. 2019;18(1):128.

21. Karam BS, Chavez-Moreno A, Koh W, Akar JG, Akar FG. Oxidative stress and inflammation as central mediators of atrial fibrillation in obesity and diabetes. Cardiovasc Diabetol. 2017:16(1):120.

22. Yao C, Veleva T, Scott L Jr, Cao S, Li L, Chen G, Jeyabal P, Pan X, Alsina KM, Abu-Taha ID, et al. Enhanced cardiomyocyte NLRP3 inflammasome signaling promotes atrial fibrillation. Circulation. 2018;138(20):2227-42.

23. Singleton MJ, German CA, Soliman EZ, Whalen SP, Bhave PD, Bertoni AG, Yeboah J. Body mass index, sex, and incident atrial fibrillation in diabetes: the ACCORD trial. JACC Clin Electrophysiol. 2020:6(13):1713-20.

24. Gallo LA, Wright EM, Vallon V. Probing SGLT2 as a therapeutic target for diabetes: basic physiology and consequences. Diab Vasc Dis Res. 2015;12(2):78-89.

25. DeFronzo RA, Hompesch M, Kasichayanula S, Liu X, Hong Y, Pfister M, Morrow LA, Leslie BR, Boulton DW, Ching A, et al. Characterization of renal glucose reabsorption in response to dapagliflozin in healthy subjects and subjects with type 2 diabetes. Diabetes Care. 2013;36(10):3169-76.

26. Trum M, Riechel J, Lebek S, Pabel S, Sossalla ST, Hirt S, Arzt M, Maier LS, Wagner S. Empagliflozin inhibits $\mathrm{Na}(+) / \mathrm{H}(+)$ exchanger activity in human atrial cardiomyocytes. ESC Heart Fail 2020.

27. Pinho-Gomes AC, Reilly S, Brandes RP, Casadei B. Targeting inflammation and oxidative stress in atrial fibrillation: role of 3-hydroxy-3-methylglutaryl-coenzyme a reductase inhibition with statins. Antioxid Redox Signal. 2014;20(8):1268-85.

28. Yurista SR, Sillje HHW, Rienstra M, de Boer RA, Westenbrink BD. Sodiumglucose co-transporter 2 inhibition as a mitochondrial therapy for atrial fibrillation in patients with diabetes? Cardiovasc Diabetol. 2020;19(1):5. 
29. Hatem SN, Sanders P. Epicardial adipose tissue and atrial fibrillation. Cardiovasc Res. 2014;102(2):205-13.

30. Sato T, Aizawa Y, Yuasa S, Kishi S, Fuse K, Fujita S, Ikeda Y, Kitazawa H, Takahashi M, Sato M, et al. The effect of dapagliflozin treatment on epicardial adipose tissue volume. Cardiovasc Diabetol. 2018;17(1):6.

31. Zelniker TA, Bonaca MP, Furtado R, Mosenzon O, Kuder JF, Murphy SA, Bhatt DL, Leiter LA, McGuire DK, Wilding JPH, et al. Effect of Dapagliflozin on Atrial Fibrillation in patients with Type 2 diabetes mellitus: insights from the DECLARE-TIMI 58 trial. Circulation. 2020:141:1227-34.

32. Okunrintemi V, Mishriky BM, Powell JR, Cummings DM. Sodium-glucose co-transporter-2 inhibitors and atrial fibrillation in the cardiovascular and renal outcome trials. Diabetes Obes Metab. 2021:23(1):276-80.

33. Alonso A, Bahnson JL, Gaussoin SA, Bertoni AG, Johnson KC, Lewis CE, Vetter M, Mantzoros CS, Jeffery RW, Soliman EZ, et al. Effect of an intensive lifestyle intervention on atrial fibrillation risk in individuals with type 2 diabetes: the Look AHEAD randomized trial. Am Heart J. 2015;170(4):770-777 e775.

34. Ball J, Lochen ML, Wilsgaard T, Schirmer H, Hopstock LA, Morseth $B$, Mathiesen EB, Njolstad I, Tiwari S, Sharashova E. Sex Differences in the Impact of body mass index on the risk of future Atrial Fibrillation: insights from the longitudinal population-based tromso study. J Am Heart Assoc. 2018;7(9):e008414.

35. Berkovitch A, Kivity S, Klempfner R, Segev S, Milwidsky A, Erez A, Sabbag A, Goldenberg I, Sidi Y, Maor E. Body mass index and the risk of new-onset atrial fibrillation in middle-aged adults. Am Heart J. 2016;173:41-8.

36. Jamaly S, Carlsson L, Peltonen M, Jacobson P, Sjostrom L, Karason K. Bariatric surgery and the risk of new-onset Atrial Fibrillation in swedish obese subjects. J Am Coll Cardiol. 2016;68(23):2497-504.

37. Huxley RR, Misialek JR, Agarwal SK, Loehr LR, Soliman EZ, Chen LY, Alonso A. Physical activity, obesity, weight change, and risk of atrial fibrillation: the atherosclerosis risk in communities study. Circ Arrhythm Electrophysiol. 2014;7(4):620-5.

38. Jones NR, Taylor KS, Taylor CJ, Aveyard P. Weight change and the risk of incident atrial fibrillation: a systematic review and meta-analysis. Heart. 2019;105(23):1799-805

39. Pereira MJ, Eriksson JW. Emerging role of SGLT-2 inhibitors for the treatment of obesity. Drugs. 2019;79(3):219-30.

40. Kahn SE, Haffner SM, Heise MA, Herman WH, Holman RR, Jones NP, Kravitz BG, Lachin JM, O'Neill MC, Zinman B, et al. Glycemic durability of rosiglitazone, metformin, or glyburide monotherapy. N Engl J Med. 2006;355(23):2427-43.

41. Morgan CL, Jenkins-Jones S, Evans M, Barnett AH, Poole CD, Currie CJ. Weight change in people with type 2 diabetes: secular trends and the impact of alternative antihyperglycaemic drugs. Diabetes Obes Metab. 2012;14(5):424-32.

42. Gerstein HC, Colhoun HM, Dagenais GR, Diaz R, Lakshmanan M, Pais $P_{\text {, }}$ Probstfield J, Riesmeyer JS, Riddle MC, Ryden L, et al. Dulaglutide and cardiovascular outcomes in type 2 diabetes (REWIND): a double-blind, randomised placebo-controlled trial. Lancet. 2019;394(10193):121-30.

43. Marso SP, Bain SC, Consoli A, Eliaschewitz FG, Jodar E, Leiter LA, Lingvay I, Rosenstock J, Seufert J, Warren ML, et al. Semaglutide and cardiovascular outcomes in patients with type 2 diabetes. N Engl J Med. 2016:375(19):1834-44.
44. Marso SP, Daniels GH, Brown-Frandsen K, Kristensen P, Mann JF, Nauck MA, Nissen SE, Pocock S, Poulter NR, Ravn LS, et al. Liraglutide and cardiovascular outcomes in type 2 diabetes. N Engl J Med. 2016;375(4):311-22.

45. Sun F, Wu S, Guo S, Yu K, Yang Z, Li L, Zhang Y, Quan X, Ji L, Zhan S. Impact of GLP-1 receptor agonists on blood pressure, heart rate and hypertension among patients with type 2 diabetes: a systematic review and network meta-analysis. Diabetes Res Clin Pract. 2015;110(1):26-37.

46. Smits MM, Muskiet MH, Tonneijck L, Hoekstra T, Kramer MH, Diamant M, van Raalte $\mathrm{DH}$. Exenatide acutely increases heart rate in parallel with augmented sympathetic nervous system activation in healthy overweight males. Br J Clin Pharmacol. 2016;81(4):613-20.

47. Fisher M, Petrie MC, Ambery PD, Donaldson J, Ye J, McMurray JJ. Cardiovascular safety of albiglutide in the Harmony programme: a meta-analysis. Lancet Diabetes Endocrinol. 2015;3(9):697-703.

48. Monami M, Nreu B, Scatena A, Giannini S, Andreozzi F, Sesti G, Mannucci E. Glucagon-like peptide-1 receptor agonists and atrial fibrillation: a systematic review and meta-analysis of randomised controlled trials. J Endocrinol Invest. 2017:40(11):1251-8.

49. Brown E, Wilding JPH, Barber TM, Alam U, Cuthbertson DJ. Weight loss variability with SGLT2 inhibitors and GLP-1 receptor agonists in type 2 diabetes mellitus and obesity: mechanistic possibilities. Obes Rev. 2019;20(6):816-28.

50. Ahmad NS, Ramli A, Islahudin F, Paraidathathu T. Medication adherence in patients with type 2 diabetes mellitus treated at primary health clinics in Malaysia. Patient Prefer Adherence. 2013;7:525-30.

51. Doehner W, Gerstein HC, Ried J, Jung H, Asbrand C, Hess S, Anker SD. Obesity and weight loss are inversely related to mortality and cardiovascular outcome in prediabetes and type 2 diabetes: data from the ORIGIN trial. Eur Heart J. 2020;41(28):2668-77.

52. Look ARG, Wing RR, Bolin P, Brancati FL, Bray GA, Clark JM, Coday M, Crow RS, Curtis JM, Egan CM, et al. Cardiovascular effects of intensive lifestyle intervention in type 2 diabetes. N Engl J Med. 2013;369(2):145-54.

53. Lan NSR, Fegan PG, Yeap BB, Dwivedi G. The effects of sodium-glucose cotransporter 2 inhibitors on left ventricular function: current evidence and future directions. ESC Heart Fail. 2019;6(5):927-35.

54. Lavie CJ, Laddu D, Arena R, Ortega FB, Alpert MA, Kushner RF. Healthy weight and obesity prevention: JACC health promotion series. J Am Coll Cardiol. 2018;72(13):1506-31.

55. Shao SC, Lin YH, Chang KC, Chan YY, Hung MJ, Kao Yang YH, Lai EC. Sodium glucose co-transporter 2 inhibitors and cardiovascular event protections: how applicable are clinical trials and observational studies to real-world patients? BMJ Open Diabetes Res Care. 2019:7(1):e000742.

56. Chan JC, Malik V, Jia W, Kadowaki T, Yajnik CS, Yoon KH, Hu FB. Diabetes in Asia: epidemiology, risk factors, and pathophysiology. JAMA. 2009:301(20):2129-40.

57. Wang D, Li Y, Lee SG, Wang L, Fan J, Zhang G, Wu J, Ji Y, Li S. Ethnic differences in body composition and obesity related risk factors: study in Chinese and white males living in China. PLOS ONE. 2011;6(5):e19835.

\section{Publisher's Note}

Springer Nature remains neutral with regard to jurisdictional claims in published maps and institutional affiliations.

Ready to submit your research? Choose BMC and benefit from

- fast, convenient online submission

- thorough peer review by experienced researchers in your field

- rapid publication on acceptance

- support for research data, including large and complex data types

- gold Open Access which fosters wider collaboration and increased citations

- maximum visibility for your research: over 100M website views per year

At $\mathrm{BMC}$, research is always in progress.

Learn more biomedcentral.com/submissions 